\title{
O PROJETO ENXURRADA DE BITS E SUA PARTICIPAÇÃO NA II SEMANA DA INOVAÇÃO
}

\author{
Maria I C da S Coutinho - mariaizamaracoutinho@gmail.com \\ André R da Cruz - dacruz@cefetmg.br \\ Sandro R Dias - sandro@decom.cefetmg.br \\ Joana A P F Avelino - joanaforte@cefetmg.br \\ Centro Federal de Educação Tecnológica de Minas Gerais / Campus II \\ Avenida Amazonas, 7675, Nova Gameleira \\ 30510-000 - Belo Horizonte - Minas Gerais
}

\begin{abstract}
Resumo: O Enxurrada de Bits é um projeto de extensão que beneficia a sociedade de todos os modos, seja com o aprendizado profissionalizante proporcionado ou com o desenvolvimento do raciocínio lógico, possuindo como objetivo promover e estimular o interesse em programação e robótica nos alunos de escolas públicas, tanto do ensino fundamental quanto do ensino médio, sendo oferecidos cursos de programação web, robótica e informática básica. Durante os dias 26/11 e 27/11 do ano de 2019, o projeto Enxurrada de Bits, em parceria com o COMPET e a Pacific Botz, ministraram oficinas de programação scratch e cubo mágico, como também realizaram uma mostra de robôs, durante a $2^{a}$ Semana da Inovação. A participação no evento se deu à um convite da FAPEMIG, patrocinadora do Enxurrada de Bits e, seu intuito na participação, foi principalmente a exposição do projeto, o que ampliaria as oportunidades existentes para futuras atividades de extensão.
\end{abstract}

Palavras-chave: Enxurrada de Bits. Semana da Inovação. Robótica. Programação. COMPET.

\section{INTRODUÇÃO}

Por meio da extensão, a universidade tem a oportunidade de levar à comunidade os conhecimentos de que é detentora, os novos conhecimentos produzidos pela pesquisa e normalmente divulgados com o ensino. É uma forma de a universidade socializar e democratizar o conhecimento, levando-o aos não universitários. Assim, o conhecimento não se traduz em privilégio apenas da minoria que é aprovada no vestibular, mas difundido pela comunidade, consoante os próprios interesses dessa mesma comunidade (SILVA, 1997). Isto posto, é de extrema importância ressaltar a manutenção e implementação de projetos de extensão nas instituições de ensino. Pode-se citar que o Centro Federal de Educação Tecnológica de Minas Gerais (CEFET-MG), assim como muitas universidades no Brasil, apoia e financia vários programas voltados para a extensão, como o Programa de Educação Tutorial do curso de Engenharia de Computação (COMPET), que tem como intuito promover projetos de ensino, pesquisa e extensão e o Enxurrada de Bits, que proporciona cursos básicos na área de tecnologia gratuitamente. A real notabilidade desses 
projetos, então, não são apenas para os membros participantes, mas também para os demais estudantes da instituição e, principalmente, para a comunidade externa.

O Enxurrada de Bits é um projeto de extensão que beneficia a sociedade de todos os modos, seja com o aprendizado profissionalizante proporcionado ou com o desenvolvimento do raciocínio lógico, possuindo como objetivo promover e estimular o interesse em programação e robótica nos alunos de escolas públicas, tanto do ensino fundamental quanto do ensino médio. Dentre as iniciativas sociais que o projeto Enxurrada de Bits exerce, pode-se citar os cursos oferecidos semestralmente, sendo programação web, robótica e informática básica, além da realização de visitas à escolas da rede pública, oferecendo minicursos em diversas áreas, tais quais como programação scratch, cubo mágico e robótica.

A $2^{\text {a }}$ Semana da Inovação aconteceu de 25 a 29 de novembro, de 2019, na Cidade Administrativa Presidente Tancredo Neves, Belo Horizonte, Minas Gerais. Este evento tem como principal objetivo fomentar a inovação dentro do Governo de Minas e demonstrar que os processos inovadores e a tecnologia apresentam várias possibilidades para a superação dos desafios do setor público (BRASIL, 2019).

O projeto foi convidado pela FAPEMIG, apoiadora do evento, e a principal patrocinadora do projeto, para ofertar atividades que demonstram o que é realizado neste programa e para auxiliar na organização do stand, sendo que outros dois projetos do CEFET-MG contribuíram. A parceria foi feita com o COMPET e a Pacific Botz - equipe de robótica aplicada a competição e desenvolvimento de robôs autônomos. Os membros de todas as equipes, juntos, ministraram oficinas de programação scratch e cubo mágico, como também realizaram uma mostra de robôs.

O intuito na participação foi principalmente a exposição e divulgação do Enxurrada de Bits, para demonstrar as capacidades e oportunidades oferecidas pelo projeto dentro do setor público, o que ampliaria as oportunidades existentes para futuras atividades de extensão. Além disso, tem por objetivo promover a compreensão de como a computação se faz presente em suas vidas e o que esperar de uma especialização nesta área. Tudo isto é conquistado a partir de práticas de programação, resolução de cubos mágicos, a mostra de robôs e, claro, o bate-papo com os monitores e coordenadores envolvidos.

\section{PLANEJAMENTO}

Planejar é decidir antecipadamente o que deve ser feito, ou seja, o planejamento deve ser o primeiro passo na organização de um evento, seja ele grande ou pequeno, pois um planejamento bem estruturado é capaz de dar a dimensão geral do evento, diminuir contratempos, além de ser um guia para todo o evento. Logo, pode-se concluir que o processo de planejamento se interessa pelos fins e pelos meios para atingir tais fins (COUTINHO, 2010), sendo imprescindível para o sucesso do evento.

Dessa forma, o COMPET se responsabilizou pelo planejamento do evento e, para que ele obtivesse êxito, foi necessário organizar o pessoal que ajudará em cada dia do evento, para que não ocorra desfalques ou falta de monitores para alguma oficina, com um total de 19 voluntários. Sendo assim, foi feita uma planilha compartilhada com todas as equipes parceiras e os voluntários que o COMPET possui cadastrados, com um limite de tempo de uma semana antes do evento.

Foram definidos que as atividades oferecidas no evento seriam programação scratch, montagem de cubos mágicos e mostra de robôs, como na maioria dos eventos oferecidos pelo Enxurrada de Bits. 
Cabe mencionar que todos os voluntários, para ajudarem nas atividades da $2^{\mathrm{a}}$ Semana da Inovação, foram alocados para uma oficina que tivessem conhecimento e, caso não conhecessem nenhuma, membros mais experientes eram incumbidos de ensiná-lo para que este pudesse atuar em alguma atividade ofertada.

Ademais, foi planejado e separado, com antecedência, todos os materiais necessários para serem levados ao evento, como, quais robôs iriam e quantos netbooks e cubos mágicos seriam necessários. Sendo que estas tarefas foram de responsabilidade dos membros da equipe Enxurrada de Bits e Pacific Botz.

Vale explicitar que, embora tudo tenha sido planejado, é preciso que as outras fases do planejamento sejam executadas, pois são essenciais. Para compreensão, pode-se explicitar que é na fase do evento que o esforço de diversos profissionais começa a se concretizar com a execução de todo o planejamento previamente estipulado (NAKANE, 2000). E, além disso, o pós-evento se faz necessário, porque é neste momento que se faz análise dos acertos e equívocos cometidos durante a realização do evento, portanto, é desejável que uma avaliação seja feita e que esta seja em reunião corn a equipe organizadora, que se ouça a opinião do cliente e utilize pesquisa de opinião dos participantes (NAKANE, 2000).

\subsection{Atividades ofertadas}

Foram ofertadas 3 atividades, sendo elas: programação scratch, montagem de cubos mágicos e mostra de robôs.

Tabela 1. Atividades ofertadas e suas informações

\begin{tabular}{|c|c|c|}
\hline Atividade & O que é? & Por quê? \\
\hline Programação scratch & $\begin{array}{l}\text { É uma linguagem de programação } \\
\text { visual que permite criar jogos, } \\
\text { animações e histórias interativas. } \\
\text { Sua dinâmica de funcionamento é } \\
\text { bem simples e intuitiva, pois } \\
\text { trabalha com blocos para montar, } \\
\text { tipo LEGO. }\end{array}$ & $\begin{array}{l}\text { Torna possível aprender } \\
\text { conceitos específicos de } \\
\text { programação de uma maneira } \\
\text { simplificada. }\end{array}$ \\
\hline Cubos mágicos & É um quebra-cabeça tridimensional. & $\begin{array}{c}\text { Resgata o gosto dos alunos } \\
\text { pela descoberta, estimula a } \\
\text { curiosidade e a } \\
\text { autoconfiança e proporciona } \\
\text { o desenvolvimento das } \\
\text { habilidades operatórias. }\end{array}$ \\
\hline Mostra de robôs & $\begin{array}{c}\text { Um robô é um dispositivo, ou grupo } \\
\text { de dispositivos, eletromecânicos } \\
\text { capazes de realizar trabalhos de } \\
\text { maneira autônoma ou } \\
\text { pré-programada. }\end{array}$ & $\begin{array}{l}\text { Melhora do raciocínio e da } \\
\text { criatividade, além de } \\
\text { prepará-los para o futuro ao } \\
\text { lidar com a tecnologia. }\end{array}$ \\
\hline
\end{tabular}

Fonte: Dados levantados pelo autor. 
$\mathrm{Na}$ oficina de programação scratch foi levado netbooks que já possuíam o programa, para que tudo pudesse ser ofertado de maneira offline, e era utilizado roteiros para que o participante tivesse um norte inicial, mas sempre estando livre para fazer qualquer atividade da sua imaginação, sempre com o respaldo de um monitor ao lado para lhe auxiliar. É válido relembrar que programação scratch não é ofertada no Enxurrada de Bits, mas optamos sempre por oferecê-lo nos eventos por ser um software construcionista e se tratar de uma linguagem de programação visual, que permite a criação de projetos multimídia, tornando possível aprender conceitos específicos de programação e fazendo do estudante o construtor de seu próprio conhecimento (HORNINK, 2018).

$\mathrm{Na}$ oficina de cubo mágico disponibilizamos um montante de cubos, principalmente os $3 \times 3$, mas também haviam $2 \times 2$, piramidal, dodecaedro e mirror blocks. Além da disponibilização dos materiais, haviam banners com passo a passo para montagem do cubo $3 \times 3$ e monitores para auxiliar na montagem dos cubos dispostos. A escolha dessa oficina foi pensada e escolhida com amparos científicos, sendo um exemplo o estudo feito por Nunes (1990, p.195): "Para um trabalho pedagógico com brinquedos, além de resgatar o gosto dos alunos pela descoberta, pelo novo, o trabalho com o lúdico proporciona também o desenvolvimento das habilidades operatórias características de cada faixa etária." e o parecer de Vigostsky (1984), que diz que o brinquedo estimula a curiosidade e a autoconfiança, proporcionando desenvolvimento da linguagem, do pensamento, da concentração e da atenção.

Já na mostra de robôs haviam diversos modelos e, principalmente, robôs de competição, como o Sumô Lego. O principal motivo de sua oferta é porque se trata de uma área que traz enormes benefícios para o aprendizado de crianças e adolescentes, como melhora do raciocínio e da criatividade, além de prepará-los para o futuro ao lidar com a tecnologia de forma positiva e produtiva (REDE BATISTA DA EDUCAÇÃO, 2019).

\section{AVALIAÇÃo}

Na visão de Matias (2003), um elemento importante para o processo de avaliação é a opinião das pessoas que compõem o grupo de trabalho no que tange ao planejamento e organização do evento. Assim, membros do COMPET foram consultados oralmente e a resposta de suas avaliações foram todas favoráveis, indicando que a equipe realizou um bom trabalho.

Já a avaliação do evento em si foi feita por meio de observação direta, um método que pode ser definido como um acompanhamento presencial do processo a ser modelado que sujeita o pesquisador a um contato mais direto com a realidade (Dias, 2014), dos participantes na concretização deste stand, em que se pôde observar um excepcional interesse do público em participar das oficinas e/ou entender um pouco mais sobre o programa Enxurrada de Bits e seu papel na sociedade. Também é válido discorrer que resultados obtidos após o evento influenciaram em sua avaliação positiva, como uma proposta de parceria com a Prefeitura de Belo Horizonte.

\section{RESULTADOS}

A presença do Enxurrada de Bits no evento trouxe visibilidade ao projeto dentro da esfera pública, em que se obtém uma parceria com a Prefeitura de Belo Horizonte para a qual se 
oferta turmas exclusivas para os professores da rede municipal de ensino. Há, também, um projeto em andamento para incluir os cursos em turmas das escolas municipais, mas ainda sem tramitação dentro da prefeitura. $\mathrm{O}$ evento deu vista, também, ao curso de Engenharia de Computação, o qual engloba a maioria dos membros do projeto, em vista que se pôde, de modo simplificado, mostrar um pouco do universo da tecnologia e explicitar acerca da graduação e suas áreas de atuação.

Atingido estes objetivos, pode-se dizer que o COMPET teve êxito em sua atividade, corroborando com sua proposta original de extensão, que é a promoção de diversos eventos e palestras, levando informação e tecnologia à comunidade.

Ademais, seria interessante a consideração de táticas para avaliar a impressão do público diante das atividades realizadas durante eventos deste tipo, em que o público é aberto. Pois, neste evento, as avaliações foram feitas por meio de observações diretas dos realizadores.

\section{Agradecimentos}

Agradecemos ao CEFET-MG pelo apoio e fomento do grupo PET, através da Diretoria de Graduação, para a realização da atividade aqui descrita, bem como o auxílio financeiro para a participação e apresentação deste trabalho no COBENGE 2020. A FAPEMIG, pois foi por meio de seu financiamento no projeto de extensão Enxurrada de Bits que tivemos a chance de participar do evento. Ao Enxurrada de Bits que nos convidaram para uma parceria, juntamente com a equipe Pacific Botz, em que nossos membros tiveram a oportunidade de ajudar na organização e comparecimento ao evento, dando suporte com o planejamento, nas oficinas e na mostra de robôs. Além de elevar o relacionamento com outras duas equipes do CEFET-MG.

Aproveitamos para agradecer, também, aos tutores do COMPET, aos colegas que colaboraram na realização da atividade e, em especial, ao Gabriel N S d'Almeida, que colaborou na confecção do relatório deste evento.

Figura 1: Alunos e orientadores no stand após a realização das atividades.

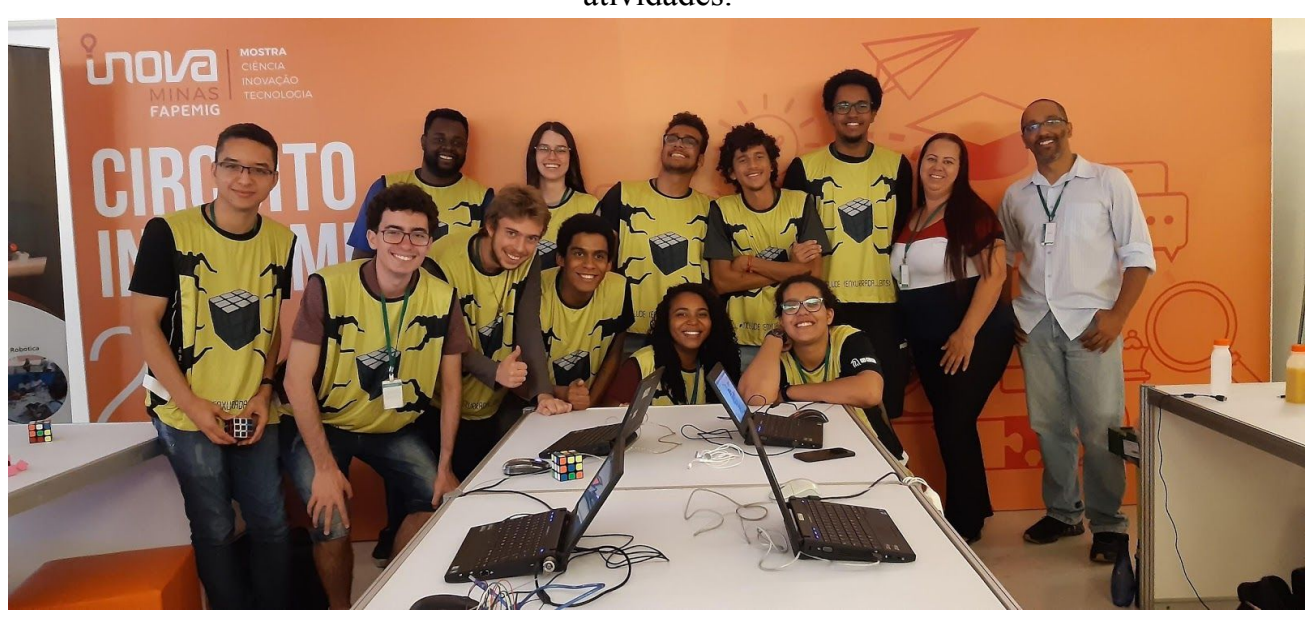

Fonte: COMPET 
(C) COBENCE 2020

"Os desafios para formar hoje o engenheiro do amanhã"

\section{Evento On-line}

\section{REFERÊNCIAS}

BRASIL. INOVA: Semana da Inovação. Disponível em: https://www.prodemge.gov.br/inova/. Acesso em: 26 Abril 2020.

COUTINHO, Helen Rita Menezes. Organização de Eventos. Manaus, p. 25. 2010. Disponível em: http://redeetec.mec.gov.br/images/stories/pdf/eixo_hosp_lazer/061112 org_eventos.pdf. Acesso em: 16 maio 2020;

DIAS, Fabiano. Métodos para levantamento de informações na Modelagem e Análise de Processos. Disponível em: https://blog.iprocess.com.br/2014/04/metodos-para-levantamento-de-informacoes/. Acesso em: 30 maio 2020;

HORNINK, Gabriel Gerber et al. Contribuições da Computação para as Tecnologias Educacionais. $1^{\text {a }}$ ed. Minas Gerais: UNIFAL-MG. 2018. p. 163-212;

MATIAS, Marlene. Organização de Eventos - Procedimentos e Técnicas. São Paulo: Manole. 2003;

NAKANE, Andrea. Técnicas de organização de eventos. Rio de Janeiro: Infobook. 2000;

Rede Batista de Educação. Qual a importância de estudar robótica na escola? Disponível em: http://blog.redebatista.edu.br/robotica-na-escola/. Acesso em: 16 de maio de 2020;

SILVA, O. da. O que é extensão universitária. Integração: ensino, pesquisa e extensão. São Paulo, v. 3, n. 9, p. 148-9. 1997;

VIGOSTSKY, L. S. A formação Social da Mente. SP: Martins Fontes, 1984. 


\title{
Evento On-line
}

\section{THE ENXURRADA DE BITS PROJECT AND ITS PARTICIPATION IN THE II SEMANA DA INOVAÇÃO}

\begin{abstract}
Enxurrada de Bits is an extension project that benefits society in all ways, whether with the professional training provided or the development of logical reasoning. The program aims to promote and stimulate interest in programming and robotics in public school students, both in elementary and high school, offering courses in web programming, robotics and basic computing. Between 11/26/2019 and 11/27/2019, the group Enxurrada de Bits, together with COMPET and Pacific Botz, ministered workshops for programming with Scratch and solving Rubik's cubes and also a showcase of the robots created by the groups were done during the 2nd Week of Innovation in Belo Horizonte. The participation of COMPET in this event was made possible through an invitation of FAPEMIG, the sponsor of Enxurrada de Bits. The aim of this was to bring more attention to the activities developed by all the three groups and, this way, enable the creation of a better network for future projects.
\end{abstract}

Keywords: Enxurrada de Bits. Semana da Inovação. Robotics. Programming. COMPET. 